\title{
Examination of the Structured Assessment of Protective Factors for Violence Risk - Youth Version (SAPROF-YV) in Canadian Adolescents
}

\author{
Aisha K. Christiansen, ${ }^{1}$ Jodi L. Viljoen, ${ }^{1}$ Erin K. Fuller ${ }^{1}$ \\ ${ }^{1}$ Department of Psychology, Simon Fraser University, Burnaby, Canada
}

\begin{abstract}
The Structured Assessment of Protective Factors for Violence Risk - Youth Version (SAPROF-YV) is a new measure of protective factors. It is used with a risk-focused tool, such as the Structured Assessment of Violence Risk in Youth (SAVRY), to provide a more balanced and comprehensive assessment of violence risk in adolescents. Our study investigated the relationship between the SAPROF-YV and aggression in a sample of 69 adolescents. Using a retrospective follow-up study design, we reviewed files at an inpatient treatment centre and a probation office. The SAPROF-YV showed good convergent and discriminant validity with the SAVRY. The SAPROF-YV was predictive of the absence of minor verbal aggression. While the SAPROF-YV added incremental predictive validity to SAVRY Protective factors for minor verbal aggression, it did not add incrementally to SAVRY Risk factors in the prediction of any type of aggression. We discuss implications for future research and clinical applications.
\end{abstract}

Keywords: protective factors, aggression, adolescence, risk assessment, violence

Several adolescent risk assessment tools have been developed to aid in the prediction and management of risk for reoffending [1]. These tools often include risk factors (i.e., factors that increase the likelihood of violence or offending) such as peer delinquency and poor parental monitoring [2]. However, several scholars have highlighted that violence risk assessments overemphasize risk factors and underemphasize protective factors $[3,4]$.

Protective factors decrease the likelihood of future violence [5-7]. For instance, support from parents, positive peer relationships, and interest in schoolwork are considered protective factors for aggression and violence [8]. Some researchers have focused on whether protective factors represent the opposite end of risk factors or if they represent unique nonoverlapping factors. Other researchers have considered whether protective factors exert main effects (i.e., direct and independent impacts) on an undesired outcome or have moderated buffering effects (i.e., dependent interactions with risk factors) to reduce negative outcomes in adolescents considered high risk [9].

Despite the debate about the conceptualization of protective factors, researchers have highlighted the importance of the inclusion of protective factors in violence risk assessment to provide a more balanced and comprehensive assessment of risk $[8,10]$. For instance, including protective factors may provide a more accurate prediction of violence risk, 
increase the focus on violence prevention [11], and promote a positive perspective for treatment providers and offenders [12].

\section{Existing Research on Measures of Protective Factors}

Although most risk assessment tools, particularly those for adults, fail to incorporate protective factors, a few tools for adolescents include protective factors. One of the most common of these tools is the Structured Assessment of Violence Risk in Youth (SAVRY) [2], which is a structured professional judgment (SPJ) tool that assesses risk for violent behaviour in adolescents. The SAVRY includes 24 risk items (rated as low, moderate, or high) within Historical, Individual/Clinical, and Social/Contextual domains, as well as six Protective factors that are rated as present or absent. In previous studies, the SAVRY has shown good predictive validity [13-16].

The predictive validity of the SAVRY Protective factors has yielded some positive findings [15,17], such as inversely predicting general reoffending [18], violence [17], and violent and general reoffending $[19,20]$. Some studies have shown mixed findings, such as predictive validity for only general reoffending [21], nonviolent reoffending [22], or only violent reoffending $[14,23]$. Further, a recent systematic review found that SAVRY Protective factors were not significantly related to violence or offending ( $k=14$ studies) [24]. These inconsistent results suggest that the SAVRY Protective factors may have limited predictive validity in some contexts and populations. As such, it may be necessary to include a more comprehensive measure of protective factors when assessing risk for violent behaviour in adolescents.

Beyond the need for further research on protective factors, there is a need for more sophisticated analyses [9], such as whether protective factors add incrementally to risk factors in the prediction of reoffending. A few studies on the SAVRY have investigated this, but findings are mixed. One study found incremental validity for SAVRY Protective factors for nonviolent reoffending only [25]. In another study, SAVRY Protective factors added incrementally to SAVRY dynamic risk factors (i.e., Individual/Clinical and Social/Contextual factors) in predicting violent reoffending [17]. In contrast, other studies found that SAVRY Protective scores do not add incrementally to SAVRY Risk total scores in the prediction of violent and nonviolent reoffending [14,20-22,26]. These findings may be due to the limited number of items on the SAVRY that assess protective factors. Further, the dichotomous response format may facilitate a loss of information (i.e., no option for a rating somewhere between present and absent).

\section{Structured Assessment of Protective Factors for Violence Risk - Youth Version}

To address gaps in the literature and in the assessment of protective factors in violence risk assessment, de Vries Robbé and colleagues developed the Structured Assessment of Protective Factors for Violence Risk - Youth Version (SAPROF-YV) [8]. This measure is designed for concurrent use with an adolescent risk assessment measure, such as the SAVRY, to provide a comprehensive assessment of violence risk. The SAPROF-YV follows an SPJ model and includes 16 protective factors with Resilience, Motivational, Relational, and External domains. Items in the Resilience domain include internal resilience and social skills. The Motivational domain is focused on the adolescent's motivation for active participation in their treatment. Items on the Relational domain concern interpersonal relationships that are prosocial, warm, and supportive. Finally, the External domain focuses on support from external sources, such as the adolescent's environment or circumstances. Each factor is rated as hardly present, present to some extent, or clearly present. All SAPROF-YV factors are considered dynamic, with the goal of bridging risk assessment with risk management by targeting adaptable protective factors during treatment. 
Thus far, research on the SAPROF-YV's reliability and validity is lacking. Unpublished pilot studies from the SAPOF-YV manual [8] ( $n=$ 76 and 37) examining adolescent files from a forensic psychiatric clinic revealed convergent validity with the SAVRY Protective factors ( $r \mathrm{~s}=$ $.63, .89$ ) and discriminant validity with SAVRY Risk factors ( $r s=-.59,-.60)$. To our knowledge, only one other study has examined psychometric properties of the SAPROF-YV. A study examining adolescent probation files in Singapore reported good to excellent internal consistency [27], but did not report on other psychometric properties (e.g., convergent or discriminant validity) of the SAPROF-YV. To our knowledge, at the time of writing there were no other published studies that have examined the SAPROF-YV and outcomes of offending or aggression.

\section{The Present Study}

Our study is one of the first independent studies to assess the predictive validity of the SAPROF-YV. We used a retrospective followup study design to examine the relationship between SAPROF-YV protective factors and aggression in adolescents from an inpatient treatment centre and a probation office. First, we examined the SAPROF-YV's convergent and discriminant validity with the SAVRY Protective and Risk factors, respectively. Second, we examined the SAPROF-YV's predictive validity for the absence of aggression. Finally, we examined the incremental predictive validity of the SAPROF-YV above SAVRY Risk and Protective factors.

\section{Methods}

\section{Sample}

Data was collected at two sites in British Columbia, Canada, including at an adolescent inpatient treatment centre and at a provincial youth probation office. We chose these settings because risk assessments are routinely conducted in these types of settings. The treatment centre provides inpatient services for adolescents aged 12 to 18 years with significant psychiatric, emotional, or behavioural issues. Files from 2011 to 2015 were included from the treatment centre's internalizing and externalizing disorders programs. The internalizing program admits many adolescents each year, so we randomly selected files from this program for inclusion in the study. The externalizing program has fewer adolescents admitted, so we used consecutive admissions to maximize the number of usable files. In addition, a random sample of adolescent probation files from 2012 to 2014 was selected as part of a larger, ongoing study.

The total sample consisted of 69 male and female adolescents aged 13 to 18 years $(M=$ $15.72, S D=1.46)$. More than half of the sample were male $(59.42 \%, n=41)$. With respect to ethnicity, $55.07 \%(n=38)$ of the sample were White, $24.64 \%(n=17)$ were Indigenous, $8.70 \%(n=6)$ were Asian, $5.80 \%(n=4)$ were Hispanic, and $5.80 \%(n=4)$ were Indian/ Middle Eastern.

Of the total sample, $56.52 \%(n=39)$ were from the treatment sample, and $43.48 \%(n=30)$ were from the probation sample. Adolescents from the two sites did not differ significantly with respect to gender $\left(X^{2}(1)=2.46, p=.12\right)$ or age $(t(67)=.16, p=.18)$. At the treatment centre, $26.09 \%(n=18)$ of adolescents were from the externalizing disorders program, and $30.43 \%(n=21)$ were from the internalizing disorders program. Adolescents from the two programs did not differ significantly with respect to gender $\left(X^{2}(1)=5.75, p=.06\right)$, age $(t(37)=.37, p=.72)$, length of treatment $(t(37)=-1.01, p=.32)$, or length of follow-up $(t(37)=-.03, p=.98)$. Therefore, adolescents from the treatment centre were considered as part of one sample (i.e., treatment sample.)

The follow-up period for the treatment sample was dependent on the adolescent's duration of stay at the treatment centre, which ranged from 1.45 to 27.56 months $(M=5.05, S D=3.79)$. The mean length of follow-up for the treatment sample was 2.63 months ( $S D=1.14$ months), as some adolescents were discharged before six months. A fixed follow-up period of six months was used for the probation sample. As 
such, the two groups had significantly different lengths of follow-up $(t(67)=-16.09, p<.01)$.

About half of the total sample had prior charges $(49.28 \%, n=34)$. Adolescents in the probation sample were significantly more likely than those in the treatment sample to have prior offences $\left(\mathrm{X}^{2}(1)=41.22, p<.01\right)$.

\section{Measures}

\section{Structured Assessment of Protective Factors for Violence Risk - Youth Version}

As described earlier, the SAPROF-YV [8] is a 16-item SPJ measure of protective factors in adolescents with four subscales: Resilience, Motivational, Relational, and External. Each item is rated on the following scale: 0 (hardly present), 1 (present to some extent), or 2 (clearly present). Raters may include plus and minus signs to indicate that a rating is slightly higher or lower, respectively. Items are rated based on information during the past six months to predict violent behaviour for the subsequent six months.

After coding the SAPROF-YV and the risk tool concurrently, the rater assigns a summary protection rating from the SAPROF-YV and a summary risk rating that considers both the SAPROF-YV and the risk tool. Both of these ratings use the following ratings: low, low-moderate, moderate, moderate-high, and high. Total scores can be created by adding the scores on all the items or by domain.

As this is a new measure, there is a lack of literature on the reliability and validity of the SAPROF-YV. Preliminary research revealed excellent internal consistency (intraclass correlation coefficients [ICCs] of .67 to .97) [27]. The pilot version showed excellent internal consistency $($ ICC $=.84, .91)$, as well as convergent validity with the SAVRY Protective factors $(r s=.63, .89)$ and discriminant validity with SAVRY Risk factors ( $r s=-.59,-.60)$ [8].

\section{Structured Assessment of Violence Risk in Youth}

The SAVRY [2] is a risk assessment tool for adolescents aged 12 to 18 years. It includes
Historical, Social/Contextual, and Individual/ Clinical factors and 24 risk items that are rated as 0 (low), 1 (moderate), or 2 (high). The total risk score is calculated by adding the risk factors. High scores are indicative of increased risk factors. Total scores are not recommended for use in clinical assessments; however, they are typically used within research contexts. The rater assigns a summary risk rating for violence risk level (i.e., low, moderate, or high). The SAVRY also includes six protective factors rated as present or absent, which may be added for a total score.

The SAVRY has demonstrated sound reliability and validity, such as excellent interrater reliability (ICC = .86) [28] and large effect sizes for the prediction of violence in a meta-analysis [29].

\section{Outcome}

Aggression outcome variables were coded using the Short-Term Assessment of Risk and Treatability (START) Outcome Scale (SOS) [30], which is derived from the Overt Aggression Scale (OAS) [31]. Outcome coding included the frequency of verbal aggression (e.g., threats) and physical aggression against others (e.g., pushing, kicking). The sos includes four levels of severity for each type of aggression. For instance, under physical aggression, a level 1 severity includes "makes threatening gestures, swings at people, grabs at clothing, throws objects dangerously" [30]. A level 4 severity of physical aggression is described as "attacks others, uses weapons, resulting in severe physical injury (e.g., fracture, loss of teeth or consciousness, lacerations, internal injury)." The SOS has shown adequate interrater reliability for inpatient populations $($ ICC $=.70)$ [32].

For our study, severity levels of 1 and 2 were collapsed to form a minor aggression category, and severity levels of 3 and 4 were collapsed to form a major aggression category for each of type of aggression. Some studies have collapsed all severity levels to look at any aggression [33]; however, scholars have cautioned against collapsing violent behaviour across severity [4]. It has been suggested that 
protective factors may have different effects across severity level [9]. Out study included a severity of level 2 in the minor category to allow for a more stringent classification of severe or major aggression.

\section{Procedure}

Ethics approval was obtained through the Office of Research Ethics at Simon Fraser University and through the research sites (i.e., treatment facility and probation).

The first author (A.K. Christiansen) completed the SAVRY and SAPROF-YV coding. She attended a day-long SAVRY training workshop. SAPROF-YV training included carefully reading the manual and completing two independent practice cases for each measure, which were compared to gold standard ratings to ensure that adequate interrater reliability (i.e., within five points on the total scores) was achieved before data collection.) In addition, the first author had previous experience delivering a day-long training on the SAPROF-YV that was developed by the SAPROF-YV authors.

\section{Treatment Sample}

At the treatment centre, files were selected if they met the following inclusion criteria:

1. were from an inpatient program,

2. the length of stay was 60 days or longer,

3. had a social and family history report, and

4. contained a psychological report.

The SAPROF-YV and SAVRY were coded using file information that was collected within the first few weeks after admission, including psychological assessment reports, and social and family history reports. The first author was kept blind to the outcomes by reviewing file information near admission/intake only.

During outcome coding, the file numbers were randomly reassigned new identification numbers. The SOS was coded by the first author (A.K. Christiansen) based on information after the psychological report interview date for up to six months. The SOS was coded using progress notes recorded by treatment staff (e.g., nurses and clinicians).

\section{Probation Sample}

A sample of probation files was randomly selected as part of a larger study's data collection. Files were included if they had a presentence report completed within the first six months of the probation order.

The first author (A.K. Christiansen) coded the SAPROF-YV and SAVRY using presentence reports and contact logs recorded by the adolescent's probation officer for the first six months postintake. She was blind to the outcomes by reviewing file information during this six-month period only. One trained research assistant coded the SOS by independently reviewing official records and contact logs during a fixed follow-up period of six months.

\section{Analyses}

\section{Convergent and Discriminant Validity}

Convergent and discriminant validity analyses were conducted with the total sample as the two samples did not show significantly different mean total scores on the SAPROF-YV and SAVRY. SAPROF-YV and SAVRY total scores were normally distributed based on visual examination of the quantile-quantile plots and histograms. Pearson bivariate correlations were conducted. Positive associations between the SAPROF-YV and SAVRY Protective factors (e.g., $r \geq .50$ ) [34] would suggest convergent validity, whereas negative associations between the SAPROF-YV and SAVRY Risk factors would indicate discriminant validity.

\section{Predictive Validity}

Predictive validity analyses were conducted by sample due to the significant difference in follow-up length. The area under the curve (AUC) value from receiver operating characteristic (ROC) analyses [35] was used to determine the accuracy of the SAPROF-YV in discriminating between adolescents who engaged in aggression and those who did not. AUC values of .556, .639, and .714 are indicative of small, moderate, and large effect sizes, respectively [36]. 
Table 1: Descriptive statistics for SAPROF-YV and SAVRY scores

\begin{tabular}{|c|c|c|c|c|c|}
\hline Measure & $\begin{array}{c}\text { Total sample } \\
(N=69) \\
M(S D)\end{array}$ & $\begin{array}{c}\text { Treatment } \\
\text { sample } \\
(n=39) \\
M(S D)\end{array}$ & $\begin{array}{c}\text { Probation } \\
\text { sample } \\
(n=30) \\
M(S D) \\
\end{array}$ & $t(d f)$ & $p$ \\
\hline \multicolumn{6}{|l|}{ SAPROF-YV } \\
\hline Total & $13.51(5.83)$ & $13.56(5.23)$ & $13.43(6.62)$ & $t(67)=.09$ & .93 \\
\hline Resilience & $2.43(2.21)$ & $2.54(1.93)$ & $2.30(2.56)$ & $t(67)=.44$ & .66 \\
\hline Motivational & $5.05(3.14)$ & $5.45(3.15)$ & $3.78(2.94)$ & $t(67)=1.41$ & .17 \\
\hline Relational & $1.88(1.32)$ & $1.87(1.28)$ & $1.90(1.40)$ & $t(67)=.09$ & .93 \\
\hline External & $4.32(1.05)$ & $3.97(.87)$ & $4.77(1.10)$ & $t(67)=-3.33$ & $<.01$ \\
\hline \multicolumn{6}{|l|}{ SAVRY } \\
\hline Risk total & $17.00(8.45)$ & $16.54(8.43)$ & $17.67(8.60)$ & $t(67)=-.53$ & .60 \\
\hline Protective & $1.80(1.63)$ & $1.62(1.35)$ & $2.03(1.94)$ & $t(67)=-1.06$ & .30 \\
\hline Historical & $6.18(4.09)$ & $5.97(4.23)$ & $6.46(3.95)$ & $t(67)=-.48$ & .63 \\
\hline Social/Contextual & $4.04(1.88)$ & $4.08(1.75)$ & $4.00(2.07)$ & $t(67)=.17$ & .87 \\
\hline Individual/Clinical & $6.78(4.36)$ & $6.49(4.58)$ & $7.27(4.11)$ & $t(67)=-.64$ & .53 \\
\hline
\end{tabular}

Table 2: Base rates of aggression

\begin{tabular}{|c|c|c|c|c|c|}
\hline Aggression & $\begin{array}{c}\text { Total sample } \\
(N=69) \\
\%(n)\end{array}$ & $\begin{array}{c}\text { Treatment } \\
\text { sample } \\
(n=39) \\
\%(n)\end{array}$ & $\begin{array}{c}\text { Probation } \\
\text { sample } \\
(n=30) \\
\%(n)\end{array}$ & $x^{2}(\mathrm{df})$ & $p$ \\
\hline \multicolumn{6}{|l|}{ Verbal } \\
\hline Minor & $49.27(34)$ & $71.79(28)$ & $20.00(6)$ & $X^{2}(1)=18.20$ & $<.01$ \\
\hline Major & $20.29(14)$ & $33.33(13)$ & $3.33(1)$ & $x^{2}(1)=9.44$ & $<.01$ \\
\hline \multicolumn{6}{|l|}{ Physical } \\
\hline Minor & $17.39(12)$ & $28.21(11)$ & $3.33(1)$ & $x^{2}(1)=7.30$ & .01 \\
\hline Major & $20.29(14)$ & $28.21(11)$ & $10.00(3)$ & $x^{2}(1)=3.48$ & .06 \\
\hline
\end{tabular}

\section{Incremental Validity}

Hierarchical logistic regression analyses were conducted to examine the incremental predictive validity of SAPROF-YV total scores above SAVRY Risk total scores, as well as above SAVRY Protective scores [37]. Block 1 included the SAVRY Risk or Protective total score, and block 2 included the SAPROF-YV total score. These analyses used the total sample. Sample site was entered as a covariate to account for differences in follow-up periods.

\section{Results}

\section{Descriptive Statistics}

Means and standard deviationsfor SAPROF-YV and SAVRY scores are presented in Table 1. For the total sample, SAPROF-YV total scores ranged from 3 to $27(M=13.51, S D=5.83)$. SAVRY Protective scores ranged from 0 to 6 $(M=1.80, S D=1.63)$. Adolescents from the two samples did not have significantly different SAPROF-YV total scores $(t(67)=.09, p=.93)$, 
Table 3: Receiver operating characteristic (ROC) analyses for verbal aggression

\section{Treatment sample}

Minor

\begin{tabular}{l} 
Measure \\
\hline SAVRY
\end{tabular}
AUC (SE) $\quad 95 \% \mathrm{Cl}$ AUC (SE) $\quad 95 \% \mathrm{Cl}$
Probation sample

Minor Major AUC (SE) $\quad 95 \% \mathrm{Cl} \quad \mathrm{AUC}(\mathrm{SE}) \quad 95 \% \mathrm{Cl}$

Risk tota

$.91^{* * *}(.05)$

$.81,1.00$

$.85^{\star \star *}(.06)$

$.73, .97$

$.73(.12)$

$.48, .97$

Risk summary

$.84^{* *}(.06)$

$.72, .96$

$.82^{* *}(.08)$

$.67, .97$

$.76(.10)$

$.56, .95$

Protective total

$.73^{*}(.09)$

$.55, .91$

.66 (.09)

$.49, .83$

$.46(.10)$

$26, .66$

SAPROF-YV

Total $.82^{* *}(.08)$

$.68, .97$

$.69(.08)$

$.53, .86$

$.65(.10)$

$.45, .86$

$.68(.08)$

$.52, .85$

$.67(.10)$

$.48, .87$

Risk summary
$.67, .94$

$.68(.10)$
$.49, .87$

$.71(.11)$

$.51, .92$

Note. ${ }^{*} p<.05,{ }^{* *} p<.01,{ }^{* * *} p<.001$. AUC = area under the curve; SE = standard error; $95 \% \mathrm{Cl}=95 \%$ confidence interval. AUC values for major verbal aggression are not presented (-) for the probation sample due to a low base rate (i.e., less than two individuals, or less than 10\%).

Table 4: Receiver operating characteristic (ROC) analyses for physical aggression

\begin{tabular}{|c|c|c|c|c|c|c|c|c|}
\hline \multirow[b]{3}{*}{ Measure } & \multicolumn{6}{|c|}{ Treatment sample } & \multicolumn{2}{|c|}{ Probation sample } \\
\hline & \multicolumn{2}{|c|}{ Minor } & \multicolumn{4}{|c|}{ Major } & \multirow{2}{*}{$\frac{\text { Minor }}{\text { AUC (SE) }}$} & \multirow{2}{*}{$\begin{array}{r}\text { Major } \\
95 \% \mathrm{Cl}\end{array}$} \\
\hline & AUC (SE) & $95 \% \mathrm{Cl}$ & AUC (SE) & $95 \% \mathrm{Cl}$ & AUC (SE) & $95 \% \mathrm{Cl}$ & & \\
\hline \multicolumn{9}{|l|}{ SAVRY } \\
\hline Risk total & $.66(.10)$ & $.47, .85$ & $.77^{\star \star}(.08)$ & $.63, .92$ & - & - & $.70(.16)$ & $.39,1.00$ \\
\hline Risk summary & $.66(.11)$ & $.46, .87$ & $.76^{*}(.09)$ & $.58, .93$ & - & - & $.51(.18)$ & $.17, .86$ \\
\hline Protective total & $.66(.09)$ & $.48, .85$ & $.64(.09)$ & $.47, .82$ & - & - & $.56(.20)$ & $.17, .94$ \\
\hline \multicolumn{9}{|l|}{ SAPROF-YV } \\
\hline Total & $.64(.09)$ & $.47, .82$ & $.68(.08)$ & $.51, .84$ & - & - & $.60(.18)$ & $.24, .96$ \\
\hline Protection summary & $.63(.09)$ & $.45, .80$ & $.68(.09)$ & $.52, .85$ & - & - & $.65(.19)$ & $.28,1.00$ \\
\hline Risk summary & $.65(.10)$ & $.46, .85$ & $.64(.10)$ & $.45, .84$ & - & - & $.55(.20)$ & $.14, .96$ \\
\hline
\end{tabular}

Note. ${ }^{*} p<.05,{ }^{* *} p<.01,{ }^{* *} p<.001$. AUC = area under the curve; SE = standard error; $95 \% \mathrm{Cl}=95 \%$ confidence interval. AUC values for minor physical aggression are not presented (-) ffor the probation sample due to a low bases rate (i.e., less than two individuals, or less than $10 \%$ ).

SAVRY Risk total scores $(t(67)=-.53, p=.60)$, or SAVRY Protective scores $(t(67)=-1.06, p=$ .30).

The two samples differed significantly for most of the aggression variables, excluding major physical aggression (see Table 2). In the treatment sample, verbal aggression was most frequent. Overall, incidents of aggression were less frequent in the probation sample than in the treatment sample. In the probation sample, base rates of major verbal aggression and minor physical aggression were less than $10 \%$. These variables were excluded from subsequent analyses for the probation sample.

\section{Convergent and Discriminant Validity Between the SAPROF-YV and the SAVRY}

As the patterns of correlations were similar across samples, the results are presented for the total sample. A large positive correlation 
Table 5: Hierarchical logistic regression analyses for the incremental validity of the SAPROF-YV total score above SAVRY Risk total scores

\begin{tabular}{|c|c|c|c|c|c|c|c|}
\hline & $b$ & $S E$ & Wald & $d f$ & p & OR & $95 \% \mathrm{Cl}$ \\
\hline \multicolumn{8}{|l|}{ Minor verbal } \\
\hline SAVRY Risk & .21 & .06 & 12.09 & 1 & $<.01$ & 1.24 & $1.10,1.39$ \\
\hline Sample & 4.03 & 1.04 & 15.08 & 1 & $<.01$ & 56.22 & $7.36,429.55$ \\
\hline Model & \multicolumn{7}{|c|}{$\mathrm{X}^{2}=39.21, p<.01$, Cox \& Snell $R^{2}=.45$, Nagelkerke $R^{2}=.60$} \\
\hline SAPROF-YV & -.05 & .10 & .23 & 1 & .63 & .95 & $.79,1.16$ \\
\hline Model & \multicolumn{7}{|c|}{$\mathrm{X}^{2}=39.44, p<.01$, Cox \& Snell $R^{2}=.45$, Nagelkerke $R^{2}=.60$} \\
\hline \multicolumn{8}{|l|}{ Major verbal } \\
\hline SAVRY Risk & .20 & .06 & 10.30 & 1 & $<.01$ & 1.22 & $1.08,1.37$ \\
\hline Sample & 3.54 & 1.25 & 8.08 & 1 & $<.01$ & 34.61 & $3.01,398.45$ \\
\hline Model & \multicolumn{7}{|c|}{$\mathrm{X} 2=26.58, \mathrm{p}<.01$, Cox $\&$ Snell $R^{2}=.33$, Nagelkerke $R^{2}=.52$} \\
\hline SAPROF-YV & .06 & .12 & .21 & 1 & .65 & 1.06 & $.83,1.34$ \\
\hline Model & \multicolumn{7}{|c|}{$\mathrm{X}^{2}=26.79, p<.01$, Cox $\&$ Snell $R^{2}=.33$, Nagelkerke $R^{2}=.52$} \\
\hline \multicolumn{8}{|l|}{ Minor physical } \\
\hline SAVRY Risk & .07 & .04 & 2.88 & 1 & .09 & 1.08 & $.99,1.17$ \\
\hline Sample & 2.50 & 1.10 & 5.14 & 1 & .02 & 12.15 & $1.40,05.11$ \\
\hline Model & \multicolumn{7}{|c|}{$\mathrm{X}^{2}=10.71, p=.01$, Cox $\&$ Snell $R^{2}=.15$ Nagelkerke $R^{2}=.24$} \\
\hline SAPROF-YV & -.06 & .10 & .33 & 1 & .57 & .95 & $.78,1.15$ \\
\hline Model & \multicolumn{7}{|c|}{$\mathrm{X}^{2}=11.04, p=.01$, Cox $\&$ Snell $R^{2}=.15$, Nagelkerke $R^{2}=.25$} \\
\hline \multicolumn{8}{|l|}{ Major physical } \\
\hline SAVRY Risk & .10 & .04 & 6.09 & 1 & .01 & 1.11 & $1.02,1.21$ \\
\hline Sample & 1.40 & .76 & 3.41 & 1 & .07 & 4.04 & $.92,17.81$ \\
\hline Model & \multicolumn{7}{|c|}{$\mathrm{X}^{2}=10.04, p=.01$, Cox $\&$ Snell $R^{2}=.14$, Nagelkerke $R^{2}=.22$} \\
\hline SAPROF-YV & -.02 & .10 & .03 & 1 & .87 & .99 & $.82,1.19$ \\
\hline Model & \multicolumn{7}{|c|}{$\mathrm{X}^{2}=10.07, p=.02$, Cox \& Snell $R^{2}=.14$, Nagelkerke $R^{2}=.22$} \\
\hline
\end{tabular}

Note. $b=$ unstandardized regression coefficient; $S E=$ standard error; $O R=$ odds ratio; $95 \% \mathrm{Cl}=95 \%$ confidence interval.

was found between the SAPROF-YV total score and the SAVRY Protective score $(r=.85$, $p<.01)$. A large negative correlation was found between the SAPROF-YV total score and the SAVRY Risk total score $(r=-.76, p<.01)$.

\section{Predictive Validity}

AUC values with $95 \%$ confidence intervals are presented in Tables 3 and 4.

For the treatment sample, SAPROF-YV total scores, SAPROF-YV summary ratings, and SAVRY Protective scores significantly predicted minor verbal aggression with large effect sizes (AUC > .71) [36]. Although these measures also predicted physical aggression with moderate AUC scores, these values did not reach significance. SAVRY Risk total scores and summary ratings significantly predicted verbal aggression and major physical aggression with large AUC scores.

In the probation sample, no AUC values reached significance. SAPROF-YV total scores and protection summary ratings had moderate AUC scores for predicting minor 
Table 6: Hierarchical logistic regression analyses for the incremental validity of the SAPROF-YV Total score above SAVRY Protective total scores

\begin{tabular}{|c|c|c|c|c|c|c|c|}
\hline & $b$ & $S E$ & Wald & $d f$ & $p$ & OR & $95 \% \mathrm{Cl}$ \\
\hline \multicolumn{8}{|l|}{ Minor verbal } \\
\hline SAVRY Protective & -.38 & .21 & 3.27 & 1 & .07 & .69 & $.46,1.03$ \\
\hline Sample & 2.36 & .61 & 15.16 & 1 & $<.001$ & 10.56 & $3.22,34.60$ \\
\hline Model & \multicolumn{7}{|c|}{$\mathrm{X}^{2}=22.93, p<.001$, Cox \& Snell $R^{2}=.28$, Nagelkerke $R^{2}=.38$} \\
\hline SAPROF-YV & -.39 & .13 & 8.96 & 1 & $<.01$ & .67 & $.52, .87$ \\
\hline Model & \multicolumn{7}{|c|}{$\mathrm{X}^{2}=35.07, p<.001$, Cox \& Snell $R^{2}=.40$, Nagelkerke $R^{2}=.53$} \\
\hline \multicolumn{8}{|l|}{ Major verbal } \\
\hline SAVRY Protective & -.52 & .29 & 3.17 & 1 & .08 & .60 & $.34,1.05$ \\
\hline Sample & 2.72 & 1.09 & 6.21 & 1 & .01 & 5.14 & $1.79,128.20$ \\
\hline Model & \multicolumn{7}{|c|}{$\mathrm{X}^{2}=15.02, p<.01$, Cox \& Snell $R^{2}=.20$, Nagelkerke $R^{2}=.31$} \\
\hline SAPROF-YV & -.16 & .11 & 2.06 & 1 & .15 & .85 & $.69,1.06$ \\
\hline Model & \multicolumn{7}{|c|}{$\mathrm{X}^{2}=17.17, p<.01$, Cox \& Snell $R^{2}=.22$, Nagelkerke $R^{2}=.35$} \\
\hline \multicolumn{8}{|l|}{ Minor physical } \\
\hline SAVRY Protective & -.47 & .30 & 2.48 & 1 & .12 & .63 & $.35,1.12$ \\
\hline Sample & 2.44 & 1.09 & 5.01 & 1 & .03 & 11.49 & $1.35,97.48$ \\
\hline Model & \multicolumn{7}{|c|}{$\mathrm{X} 2=11.55, p<.01$. Cox $\&$ Snell $R^{2}=.15$, Nagelkerke $\mathrm{R} 2=.26$} \\
\hline SAPROF-YV & -.05 & .11 & .22 & 1 & .64 & .95 & $.76,1.18$ \\
\hline Model & \multicolumn{7}{|c|}{$\mathrm{X}^{2}=11.77, p=.01$, Cox $\&$ Snell $R^{2}=.16$, Nagelkerke $R^{2}=.26$} \\
\hline \multicolumn{8}{|l|}{ Major physical } \\
\hline SAVRY Protective & -.28 & .24 & 1.40 & 1 & .24 & .76 & $.48,1.20$ \\
\hline Sample & 1.22 & .71 & 2.92 & 1 & .09 & 3.38 & $.84,13.64$ \\
\hline Model & \multicolumn{7}{|c|}{$\mathrm{X}^{2}=5.27, p=.07$, Cox \& Snell $R^{2}=.07$, Nagelkerke $\mathrm{R} 2=.12$} \\
\hline SAPROF-YV & -.17 & .11 & 2.48 & 1 & .12 & .85 & $.69,1.04$ \\
\hline Model & \multicolumn{7}{|c|}{$\mathrm{X}^{2}=7.83, p=.05$, Cox \& Snell $R^{2}=.11$, Nagelkerke $R^{2}=.17$} \\
\hline
\end{tabular}

Note. $b=$ unstandardized regression coefficient; $S E=$ standard error; $O R=$ odds ratio; $95 \% \mathrm{Cl}=95 \%$ confidence interval.

verbal aggression and major physical aggression. SAVRY Protective scores had chancelevel AUC scores. In contrast, SAVRY Risk total scores showed a large AUC score for minor verbal aggression and a moderate AUC score for major physical aggression.

\section{Incremental Predictive Validity Above SAVRY Risk or Protective} Factors

SAPROF-YV total scores did not significantly predict aggression beyond SAVRY Risk total scores (see Table 5). The SAPROF-YV total score only significantly predicted minor verbal aggression beyond the SAVRY Protective scores. SAVRY Protective scores did not predict aggression (see Table 6).

\section{Discussion}

As the SAPROF-YV is a relatively new measure, research needs to evaluate its psychometric properties [8]. Our research is one of the first studies to examine the validity of the SAPROF-YV and the first to examine the SAPROV-YV's psychometric properties in a Western Canadian sample. Moreover, our 
study included adolescents from both an inpatient treatment centre and probation.

Overall, the results supported the convergent and discriminant validity of the SAPROF-YV. Consistent with the pilot studies [8], the SAPROF-YV had a large positive correlation with SAVRY Protective factors (i.e., $r>$.50) [34] and a large inverse correlation with SAVRY Risk factors. While pilot research focused on adolescent forensic samples [8], our results suggest that convergent and discriminant validity with the SAVRY may be generalizable to both forensic and psychiatric samples of adolescents.

The SAPROF-YV total score and protection summary risk rating were significant predictors of (the absence of) minor verbal aggression in the treatment sample, which was the most common and frequent form of aggression. Although past research has focused on physical aggression, or has collapsed verbal and physical aggression [38], verbal aggression may be important to examine because it is common in inpatient settings. Few adolescent risk assessment studies have been conducted with psychiatric samples, but our study found that base rates of some forms of aggression were fairly high (e.g., greater than SOS rates in adult inpatient samples) [33], suggesting that it may be important to regularly assess risk in this population. Further, instances of verbal aggressions (e.g., threats to others) might trigger or escalate to physical violence. While the SAPROF-YV did not significantly predict physical aggression, effect sizes were within the moderate range.

Although many researchers and practitioners consider the assessment of protective factors to be important, there is uncertainty about whether protective factors add to predictions beyond risk factors. In our study, SAPROF-YV total scores did not predict aggression beyond SAVRY Risk factors. Previous research has shown inconsistent findings about the incremental validity of protective factors over risk factors $[22,25,26]$. These findings suggest that the variance captured by protective factors may be explained by risk factors. In addition, predictive validity effect sizes were generally higher for the SAVRY Risk factors compared with the SAPROF-YV protective factors. Thus, risk factors may appear more useful for risk prediction, but it is still unknown whether protective factors have added usefulness for violence prevention and risk management.

One of the primary rationales for the development of the SAPROF-YV was that existing measures of protective factors, such as on the SAVRY, are brief. Further, brief measures of protective factors (i.e., the SAVRY) tend to capture mainly deficits in protective factors (i.e., low scores), as opposed to the presence of protective factors [20]. In our study, the SAPROF-YV showed incremental predictive validity over SAVRY Protective factors for minor verbal aggression, suggesting that it contributed more information than is captured by the SAVRY Protective factors alone. However, the SAPROF-YV did not outperform the SAVRY Protective factors in the prediction of physical aggression, despite being a lengthier tool (i.e., 16 ordinal items on SAPROF-YV versus six dichotomous items on the SAVRY).

\section{Implications and Future Directions}

As the SAPROF-YV is a relatively new tool, there is limited research on its psychometric properties. There are two main implications from our findings. First, research should continue to examine the predictive validity of this tool with adolescents, particularly for physical aggression. Future research should also examine the specific effects of individual protective factors. The SAPROF-YV manual acknowledges that some factors have limited empirical support, such as Social Competence and Court Order [8], and these factors require further validation to support their inclusion in the tool. Additionally, different factors may have greater predictive validity in different subsamples of adolescents (e.g., by gender, by forensic versus mental health settings). For instance, Prosocial Involvement on the SAVRY has been associated with future violence in girls but not in boys [39]. In our study, 
gender differences were not examined due to the small sample size.

Second, research should examine how the implementation of the SAPROF-YV in realworld settings impacts treatment and management decisions. For instance, implementing the SAVRY has led to an increased consideration of protective factors in determining supervision levels for adolescent offenders, as well as a greater match between needs, protective factors, and service recommendations from youth justice professionals [40]. In clinical settings, protective factors may be valuable targets for interventions [41], such as by leveraging or improving protective factors that are present or lacking, respectively. However, there is a lack of literature examining strength-based intervention planning, so it requires further examination [41].

\section{Limitations}

The main limitation of our study is the small sample size and low power. Although the total sample size is comparable to some studies $[42,43]$ and expands on pilot research on the SAPROF-YV (e.g., $n=37$ ) [8], it was nevertheless smaller than ideal. For instance, the SAPROF-YV had moderate effect sizes for predicting physical aggression, which did not reach significance. This may be due to a lack of power. Future research should include larger samples of adolescents to see if the SAPROF-YV may be a significant predictor of physical aggression.

In addition, the use of inpatient and community samples resulted in differences in the quality of information used for outcome coding. Adolescents in the treatment sample were under extensive supervision by staff, whereas the adolescents in the probation sample had relatively infrequent observations from their probation officers (e.g., weekly or biweekly), which limited opportunities to observe aggression. It is also likely that official records did not detect instances of minor aggression that may have been observed by staff in an inpatient setting. Therefore, the low base rates within the probation sample may be attributed to the quality of the data sources rather than true differences in rates of these behaviours across samples.

The retrospective study design is another limitation. However, file information was comprehensive, and cases were excluded if the information was insufficient for coding. Moreover, this retrospective design was consistent with most studies on risk assessment $[44,45]$.

\section{Conclusion}

Our results provide preliminary support for the psychometric properties of the SAPROF-YV. Both the SAPROF-YV and SAVRY were predictive of verbal aggression. The SAPROF-YV demonstrated incremental predictive validity for the absence of minor verbal aggression over SAVRY Protective factors. However, the SAPROF-YV did not show incremental predictive validity for other aggression variables or over the SAVRY Risk factors. These results suggest that further validation studies are needed with large, adolescent offender samples. More generally, advancing research on protective factors and assessment of strengths may be beneficial in decreasing adolescent offending.

Acknowledgement: This work was supported by the Social Sciences and Humanities Research Council of Canada.

\section{Conflict of Interest: None}

\section{References}

1. Viljoen JL, Gray AL, Barone C. Assessing risk for violence and offending in adolescents. In: Jackson R, Roesch R, editors. Learning forensic assessment: Research and practice 2nd edition. New York, NY: Routlege; 2016. p. 357-388.

2. Borum R, Bartel P, Forth A. Manual for the Structured Assessment for Violence Risk in Youth (SAVRY). Odessa, FL: Psychological Assessment Resources; 2006.

3. Hart SD. Preventing violence: The role of risk assessment and management. In: Baldry AC, Winkel FW, editors. Intimate partner violence prevention and intervention: The risk assessment and management approach. 
Hauppauge, NY: Nova Science Publishers; 2008. p. 7-18.

4. Rogers R. The uncritical acceptance of risk assessment in forensic practice. Law and Human Behavior. 2000;24(5):595-605. https://doi.org/10.1023/A:1005575113507.

5. de Vogel V, De Ruiter C, Bouman Y, de Vries Robbé M. SAPROF. Guidelines for the assessment of protective factors for violence risk (2nd ed.). Utrecht, The Netherlands: Van der Hoeven Kliniek; 2012.

6. de Vries Robbé M, de Vogel V, Wever EC, Douglas KS, Nijman HI. Risk and protective factors for inpatient aggression. Criminal Justice and Behavior. 2016;43(10):1364-1385. https://doi.org/10.1177/0093854816637889.

7. Dubow EF, Huesmann LR, Boxer P, Smith C. Childhood and adolescent risk and protective factors for violence in adulthood. Journal of Criminal Justice. 2016;45(C):26-31. https://doi.org/10.1016/j.jcrimjus.2016.02.005.

8. de Vries Robbé M, Geers MCK, Stapel $\mathrm{M}$, Hilterman ELB, Vogel V. SAPROF-YV. Structured Assessment of Protective Factors for violence risk - Youth Version (SAPROF-YV). Utrecht, The Netherlands: Van der Hoeven Kliniek; 2015.

9. Lösel F, Farrington DP. Direct protective and buffering protective factors in the development of youth violence. American Journal of Preventive Medicine. 2012;43(2, Suppl 1):S8-S23. https://doi.org/10.1016/j.amepre.2012.04.029.

10. de Vries Robbé M. Protective factors: Validation of the Structured Assessment of Protective Factors for violence risk in forensic psychiatry [dissertation]. Utrecht: Van der Hoeven Kliniek, The Netherlands; 2014.

11. de Vries Robbé M, de Vogel V. Protective factors for violence risk: Bringing balance to risk assessment and management. In: Logan C, Johnstone L, editors. Managing Clinical Risk. New York, NY: Routledge; 2012. p. 293-310.

12. Seligman MEP. Positive psychology, positive prevention, and positive therapy. In: Snyder CR, Lopez SJ, editors. Handbook of Positive Psychology. New York, NY: Oxford University Press 2002. p. 3-9.
13. Borum R, Lodewijks H, Bartel PA, Forth AE. Structured Assessment of Violence Risk in Youth (SAVRY). In: Douglas K, Otto R, editors. Handbook of Violence Risk Assessment. New York, NY: Routledge; 2010. p. 63-80.

14. Hilterman ELB, Nicholls TL, van Nieuwenhuizen C. Predictive validity of the risk assessments in juvenile offenders: Comparing the SAVRY, PCL:YV, and YLS/ $\mathrm{CMI}$ with unstructured clinical assessments. Assessment. 2014;21(3):324-339. https://doi.org/10.1177/1073191113498113.

15. Lodewijks HB, Doreleijers TH, de Ruiter C, Borum R. Predictive validity of the Structured Assessment of Violence Risk in Youth (SAVRY) during residential treatment. International Journal of Law and Psychiatry. 2008;31(3):263-271. https://doi.org/10.1016/j.ijlp.2008.04.009.

16. Olver ME, Stockdale KC, Wormith JS. Risk assessment with young offenders: A meta-analysis of three assessment measures. Criminal Justice and Behavior. 2009;36(4):329-353. https://doi. org/10.1177/0093854809331457.

17. Lodewijks HPB, de Ruiter C, Doreleijers TAH. The impact of protective factors in desistance from violent reoffending: A study in three samples of adolescent offenders. Journal of Interpersonal Violence. 2010;25(3):568-587. https://doi.org/10.1177/0886260509334403.

18. Shepherd SM, Luebbers S, Ogloff JRP, Fullam R, Dolan M. The predictive validity of risk assessment approaches for young Australian offenders. Psychiatry, Psychology and Law. 2014;21(5):801-817. https://doi.org/10.1080/13218719.2014.904262.

19. McLachlan K, Gray AL, Roesch R, Douglas $\mathrm{KS}$, Viljoen JL. An evaluation of the predictive validity of the SAVRY and YLS/CMI in justiceinvolved youth with fetal alcohol spectrum disorder. Psychological Assessment. 2018;30(12):1640-1651. https://doi.org/10.1037/pas0000612.

20. Viljoen JL, Bhanwer AK, Shaffer CS, Douglas KS. Assessing protective factors for adolescent offending: A conceptually informed examination of the SAVRY and YLS/CMI. Assessment. [Advanced online publication.] 
2018;27(5):959-975.

https://doi.org/10.1177/1073191118768435.

21. Chu CM, Goh ML, Chong D. The predictive validity of SAVRY ratings for assessing youth offenders in Singapore: A comparison with YLS/CMI ratings. Criminal Justice and Behavior. 2016;43(6):793-810. https://doi.org/10.1177/0093854815616842.

22. Penney SR, Lee Z, Moretti MM. Gender differences in risk factors for violence: An examination of the predictive validity of the Structured Assessment of Violence Risk in Youth. Aggressive Behavior. 2010;36(6), 390-404. https://doi.org/10.1002/ab.20352.

23. Zhou J, Witt K, Cao X, Chen C, Wang X. Predicting reoffending using the Structured Assessment of Violence Risk in Youth (SAVRY): A 5-year follow-up study of male juvenile offenders in Hunan Province, China. PLOS ONE. 2017;12(1):e0169251. https://doi.org/10.1371/journal.pone.0169251.

24. Dickens GL, O'Shea LE. Protective factors in risk assessment schemes for adolescents in mental health and criminal justice populations: A systematic review and meta-analysis of their predictive validity. Adolescent Res Rev. 2018;3(1):95-112. https://doi.org/10.1007/s40894-017-0062-3.

25. Dolan MC, Rennie CE. The Structured Assessment of Violence Risk in Youth as a predictor of recidivism in a United Kingdom cohort of adolescent offenders with conduct disorder. Psychological Assessment. 2008;20(1):35-46. https://doi.org/10.1037/1040-3590.20.1.35.

26. Schmidt F, Campbell MA, Houlding C. Comparative analyses of the YLS/CMI, SAVRY, and PCL:YV in adolescent offenders: A 10-year follow-up into adulthood. Youth Violence and Juvenile Justice. 2011;9(1):23-42. https://doi.org/10.1177/1541204010371793.

27. Li D, Chu CM, Xu X, Zeng G, Ruby K. Risk and protective factors for probation success among youth offenders in Singapore. Youth Violence and Juvenile Justice. 2019;17(2):194-213. https://doi.org/10.1177/1541204018778887.
28. Vincent GM, Guy LS, Fusco SL, Gershenson BG. Field reliability of the SAVRY with juvenile probation officers: Implications for training. Law and Human Behavior. 2012;36(3):225236. https://doi.org/10.1037/h0093974.

29. Singh JP, Grann M, Fazel S. A comparative study of violence risk assessment tools: A systematic review and metaregression analysis of 68 studies involving 25,980 participants. Clinical Psychology Review. 2011;31(3):499-513. https://doi.org/10.1016/j.cpr.2010.11.009.

30. Nicholls TL, Gagnon N, Crocker AG, Brink J, Desmarais S, Webster C. START Outcomes Scale (SOS). Vancouver, Canada: Mental Health \& Addiction Services; 2007.

31. Yudofsky SC, Silver JM, Jackson W, Endicott J, Williams D. The Overt Aggression Scale for the objective rating of verbal and physical aggression. The American Journal of Psychiatry. 1986;143(1):35-39. https://doi.org/10.1176/ajp.143.1.35.

32. Braithwaite E, Charette Y, Crocker AG, Reyes A. The predictive validity of clinical ratings of the Short-Term Assessment of Risk and Treatability (START). International Journal of Forensic Mental Health. 2010;9(4):271-281. https://doi.org/10.1080/14999013.2010.534378.

33. Desmarais SL, Nicholls TL, Wilson CM, Brink J. Using dynamic risk and protective factors to predict inpatient aggression: Reliability and validity of START assessments. Psychological Assessment. 2012;24(3):685-700. https://doi.org/10.1037/a0026668.

34. Cohen J. Statistical power analysis for the behavioral sciences (2nd ed.). Hillsdale, $\mathrm{NJ}$ : Lawrence Erlbaum Associates; 1988.

35. Hanley JA, McNeil BJ. The meaning and use of the area under a receiver operating characteristic (ROC) curve. Radiology. 1982;143(1):29-36. https://doi.org/10.1148/ radiology.143.1.7063747.

36. Rice ME, Harris GT. Comparing effect sizes in follow-up studies: ROC Area, Cohen's d, and r. Law and Human Behavior. 2005;29(5):615-620. https://doi.org/10.1007/s10979-005-6832-7. 
37. Hunsley J, Meyer GJ. The incremental validity of psychological testing and assessment: Conceptual, methodological, and statistical issues. Psychological Assessment. 2003;15(4):446-455. https://doi.org/10.1037/1040-3590.15.4.446.

38. Nagin D, Tremblay RE. Trajectories of boys' physical aggression, opposition, and hyperactivity on the path to physically violent and nonviolent juvenile delinquency. Child Development. 1999;70(5):1181-1196. https://doi.org/10.1111/1467-8624.00086.

39. Sijtsema JJ, Kretschmer T, van Os T. The Structured Assessment of Violence Risk in Youth in a large community sample of young adult males and females: The TRAILS study. Psychological Assessment. 2015;27(2):669677. https://doi.org/10.1037/a0038520.

40. Vincent GM, Paiva-Salisbury ML, Cook NE, Guy LS, Perrault RT. Impact of risk/ needs assessment on juvenile probation officers' decision making: Importance of implementation. Psychology, Public Policy, and Law. 2012;18(4):549-576. https://doi.org/10.1037/a0027186.

41. Singh JP, Desmarais SL, Sellers BG, Hylton T, Tirotti M, Van Dorn RA. From risk assessment to risk management: Matching interventions to adolescent offenders' strengths and vulnerabilities. Children and Youth Services
Review. 2014;47(Part 1):1-9.

https://doi.org/10.1016/j.childyouth.2013.09.015.

42. Klein V, Rettenberger M, Yoon D, Köhler N, Briken P. Protective factors and recidivism in accused juveniles who sexually offended. Sexual Abuse. 2015;27(1):71-90. https://doi.org/10.1177/1079063214554958.

43. Lodewijks HPB, de Ruiter C, Doreleijers $\mathrm{TAH}$. Gender differences in violent outcome and risk assessment in adolescent offenders after residential treatment. International Journal of Forensic Mental Health. 2008;7(2):133-146. https://doi.org/10.1080/1 4999013.2008.9914410.

44. Campbell MA, French S, Gendreau P. The prediction of violence in adult offenders: A meta-analytic comparison of instruments and methods of assessment. Criminal Justice and Behavior. 2009;36(6):567-590. https://doi.org/10.1177/0093854809333610.

45. Yang M, Wong SCP, Coid J. The efficacy of violence prediction: A meta-analytic comparison of nine risk assessment tools. Psychological Bulletin. 2010;136(5):740-767. https://doi.org/10.1037/a0020473.

\section{Corresponding author}

Dr. Jodi L. Viljoen, Department of Psychology, Simon Fraser University, Burnaby, BC V5A 1 S6 Canada - email: jviljoen@sfu.ca 